Governing Ideas 
A volume in the series

Cornell Studies in Political Economy Edited by Peter J. Katzenstein

A full list of titles in the series appears at the end of the book. 


\title{
Governing Ideas
}

\section{STRATEGIES FOR INNOVATION \\ IN FRANCE AND GERMANY}

\author{
J. Nigholas Ziegler
}

Cornell University Press

Ithaca and London 


\section{Copyright $(1997$ by Cornell University}

All rights reserved. Except for brief quotations in a review, this book, or parts thereof, must not be reproduced in any form without permission in writing from the publisher. For information, address Cornell University Press, Sage House, $5^{12}$ East State Street, Ithaca, New York 1485 o.

First published 1997 by Cornell University Press First printing, Cornell Paperbacks, 1997

\section{Ziegler, J. Nicholas}

Governing ideas : strategies for innovation in France and Germany

/ J. Nicholas Ziegler.

p. cm. - (Cornell studies in political economy)

Includes index.

ISBN o-8014-3311-8 (alk. paper). — ISBN o-8014-8371-9 (pbk. : alk. paper)

1. Technological innovations-Economic aspects-France.

2. Technological innovations-Economic aspects-Germany.

3. Technology and state-France. 4. Technology and state-Germany.

I. Title. II. Series.

HC28o.T $4 Z_{54} 1997$

$33^{\prime} .064^{\prime} \mathrm{og} 43-\mathrm{dc} 21$

Cloth printing $\quad 10987654321$ 